\title{
Response of UHPFRCs in Tension under High Stress Rate
}

\author{
Svatopluk Dobruský ${ }^{1}$, Daniele Forni $^{2}$, and Ezio Cadoni ${ }^{2, *}$ \\ ${ }^{1}$ R\&D LafargeHolcim, 38291 Saint-Quentin Fallavier, France \\ ${ }^{2}$ DynaMat Laboratory, University of Applied Sciences of Southern Switzerland, 6952 Canobbio, Switzerland
}

\begin{abstract}
The paper presents a part of a full-experimental campaign characterizing various Ductal ${ }^{\circledR}$ mix designs (compressive strength of $150,170,210 \mathrm{MPa}$ ) with various dosages of fibers ( $2 \%$ and $3.25 \%)$. The dynamic tests are performed by means of two Modified Hopkinson Bar devices with that are installed at the DynaMat Laboratory in Lugano. The tests, in tension at different velocities were performed on cylindrical notched specimens of $60 \mathrm{~mm}$ in diameter and $60 \mathrm{~mm}$ height (notch/radius $=0.20$ ). The preliminary results present different rate sensitivity of the materials. Different behaviours are registered for the materials having matrix with special thermal curing respect to those cured as usual. An important increment of stress was obtained for the matrix where sand was partially replaced by Silica Fume. These results are the base for better understanding the mechanical behaviour in dynamic that will be obtained by further tests on UltraHigh Performance Fibre-Reinforced Concretes (various Ductal ${ }^{\circledR}$ classes). Such data will provide designers better overview of relevant properties of these materials for design of protective structures.
\end{abstract}

\section{Introduction}

Nowadays, the most promising advanced materials in the construction industry are the Ultra-High Performance Fibre-Reinforced Concretes (UHPFRCs). These materials were introduced for the first time in the end of the last century [1-4]. They are modern cementitious composite materials combining cement-based matrix with a low water-to-cement ratio and reinforcing fibres. Thanks to their advanced characteristics in terms of mechanical properties, durability and aesthetics, UHPFRCs have definitely earned the trust of a growing number of designers, and is more and more adopted in many applications such as structural refurbishment and reinforcement, facade and critical infrastructures (bridges, off-shores, high-rise buildings, etc.). They have outstanding strength (120-250 MPa) and the amount of fibers ( $>2 \%$ per volume) is significantly higher than for ordinary fiber-reinforced concrete (FRC, around $0.5 \%$ per volume) which brings interesting properties from structure perspective as the final elements are often designed without any additional reinforcement. In fact, contrarily to the plain concrete UHPFRCs no contain coarse aggregates [5] and they have the capacity to resist to further loading also after the first crack. These materials react to high loading with multiple cracking, providing higher dissipation of energy by the bridging of crack mouths through pull-out of the fibres. The combination of ultra-high strength and huge energy dissipation mark these materials as very competitive candidates for the use in protective structures.

Actually, many academic teams started to suggest protective solutions made of UHPFRC for impact, blast, as well as close charge [6-8]. High strain rate mechanical properties are crucial parameters for meaningful design and analysis of protective structures. As reported in [9-10], presently in literature only limited amounts of data are available for UHPFRCs in direct tension under high loading rates. This lack of information has to be rapidly filled up, specially to answer the needs of the designers. Unfortunately, almost every paper focused on UHPFRC used only one material with one set of mechanical properties. This situation is rather difficult for design as many variations of UHPFRC exists such as a fibre dosage, orientation of fibres, a quantity of pozzolanic materials, or curing conditions which all lead to various mechanical properties. The aim of the present paper is presents the initial results of a comprehensive experimental campaign characterizing various Ductal ${ }^{\circledR}$ mix designs with various dosages of fibers ( $2 \%$ and $3.25 \%$ ).

\section{Materials}

Nine various Ductal ${ }^{\circledR}$ products were used in this study. The three compressive strengths (150 MPa, $170 \mathrm{MPa}$, $210 \mathrm{MPa}$ ) were obtained by three different matrices A, $\mathrm{B}$, and $\mathrm{C}$, respectively. The main difference between matrices is that Matrix A has no pozzolanic material; Matrix B uses 150-200 kg of Silica Fume as a replacement of sand, and Matrix $\mathrm{C}$ is made of the same premix as Matrix B but cured for $48 \mathrm{~h}$ at $90{ }^{\circ} \mathrm{C}$ and 100RH after demolding $(\sim 24 \mathrm{~h})$. The nine variations of the Ductal ${ }^{\circledR}$ products are reached by three volumetric dosages $(0 \%, 2 \%$, and $3.25 \%)$ of steel micro fibers $(0.2 / 14 \mathrm{~mm}, 2500 \mathrm{MPa})$.

Corresponding author: ezio.cadoni@supsi.ch 
In total, 45 notched UHPC cylinders of $\varnothing 20 \mathrm{~mm} / 20 \mathrm{~mm}$ and 30 notched UHPFRC cylinders of $\varnothing 60 \mathrm{~mm} / 60 \mathrm{~mm}$ were prepared. The $\varnothing 20 \mathrm{~mm}$ cylinders were drilled out of 200/300/40 mm casted slabs (15 samples per a slab; one slab per each matrix) whereas the $\varnothing 60 \mathrm{~mm}$ cylinders were drilled out of 100/100/400 mm prims (5 samples per each material combination; 3 matrices and 2 dosages of fibres). The notches were done after drilling with a depth of $20 \%$ of its diameter. The samples were casted and cured at LafargeHolcim research centre in France in laboratory conditions. The pouring of the slabs was done from the middle as there were no fibres whereas the pouring of the prisms was done from one side to keep the same fibre orientation (the samples were drilled out along the length/pouring). Fig 1 shows samples after drilling and notching.
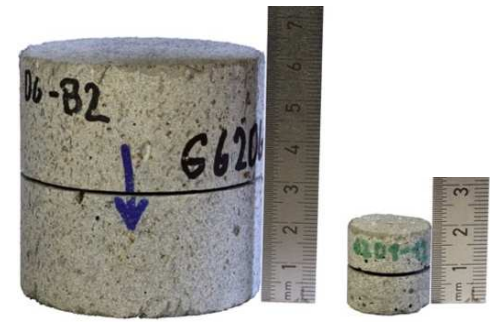

Fig. 1. Samples of UHPFRC (60 mm) and UHPC (20 mm).

Quasi-static mechanical properties of the various Ductal $^{\circledR}$ classes were tested at LafargeHolcim research center on at least 6 samples for each property according to NF P 18-470[11]. Table 1 shows mean compressive strength $\left(\mathrm{f}_{\mathrm{cm}}\right)$, mean tensile strength $\left(\mathrm{f}_{\mathrm{ct}, \mathrm{m}}\right)$ derived from a bending test reduced by a coefficient (eq. D.1 [11]), and mean tensile post-peak resistance $\left(\mathrm{f}_{\mathrm{ctfm}}\right)$ measured at 0.3 $\mathrm{mm}$ crack opening.

Table 1. Quasi-static mechanical properties of the various Ductal ${ }^{\circledR}$ products.

\begin{tabular}{|c|c|c|c|c|}
\hline Matrix & $\begin{array}{c}\mathbf{f}_{\mathrm{cm}} \\
{[\mathrm{MPa}]} \\
\end{array}$ & $\begin{array}{c}\mathbf{E}_{\mathbf{c}} \\
{[\mathrm{GPa}]} \\
\end{array}$ & $\begin{array}{r}\mathbf{f}_{\mathrm{ct}, \mathrm{m}} \\
{[\mathrm{MPa}]} \\
\end{array}$ & $\begin{array}{c}\mathbf{f}_{\mathrm{ctfm}} \\
(\mathbf{2 . 0 0 \% / 3 . 2 5 \% )} \\
{[\mathrm{MPa}]} \\
\end{array}$ \\
\hline A & 150 & 55 & 8.3 & $8.9 / 12.8$ \\
\hline B & 170 & 60 & 11.0 & $10.2 / 11.4$ \\
\hline $\mathrm{C}$ & 210 & 60 & 10.5 & 12.4/XXX \\
\hline
\end{tabular}

\section{Experimental set-ups}

To study the effects of the stress rate on these ultra-highperformance materials (fibre-reinforced and not) two different modified Hopkinson bar devices in tension have been used. In particular, the matrix A, B and C have been tested by means of the Modified Hopkinson Bar [12-25] having input and output bars with $20 \mathrm{~mm}$ in diameter and made in aluminium alloy 6082-T6, with a length of 3 and $6 \mathrm{~m}$, respectively. The cylindrical specimens of the three matrixes (A, B, and $\mathrm{C})$, have a diameter of $20 \mathrm{~mm}$ and diameter/height ratio equal to 1 . They are glued between the two bars by an epoxy resin. The specimens have been pre-notched (notch/radius = $0.20)$ in order to prevent multiple fractures. The generation of the dynamic pulse in the MHB device is obtained by statically pulling a pre-tensioned bar and suddenly release the blocking system, by rupturing a fragile bolt. The pre-tension bar is a bar, having circular cross-section, made in high strength steel C85 $\left(\mathrm{R}_{\mathrm{m}}=1256\right.$ $\mathrm{MPa}$ ) according to European Standard EN10204, with a diameter of $12 \mathrm{~mm}$ and a length of $6 \mathrm{~m}$. It is connected in an end with the hydraulic actuator and in the other end is directly connected, by screwing, to the input bar. The pre-tensioned bar has the same acoustical impedance of the input bar in order to avoid any spurious reflections in this interface. The abruptly release of the blocking system causes a rectangular shape wave (with $2.4 \mathrm{~ms}$ duration) with small rise-time (about $60 \mu \mathrm{s}$ ) that is transmitted along the input bar-specimen-output bar, till to the complete separation in two halves of the specimen. This is a uniaxial elastic plane stress wave, as the wavelength of the pulse is long compared to the bar transverse dimensions, and the pulse amplitude does not exceed the yield strength of the bar. Consequently, it is possible to use the formulation of the Split Hopkinson Bar for the stress, strain and strain rate:

$$
\begin{gathered}
\sigma(t)=E_{0} \frac{A_{0}}{A_{s}} \varepsilon_{T}(t) \\
\varepsilon(t)=-\frac{2 C_{0}}{L_{s}} \int_{0}^{t} \varepsilon_{R}(t) d t \\
\dot{\varepsilon}(t)=-\frac{2 C_{0}}{L_{s}} \varepsilon_{R}(t)
\end{gathered}
$$

where: $E_{0}$ is the bar modulus of elasticity; $A_{0}$ and $A_{s}$ are bar and specimen cross-section areas, respectively; $C_{0}$ is the elastic wave velocity; $\varepsilon_{R}$ and $\varepsilon_{T}$ are the reflected and the transmitted pulses.

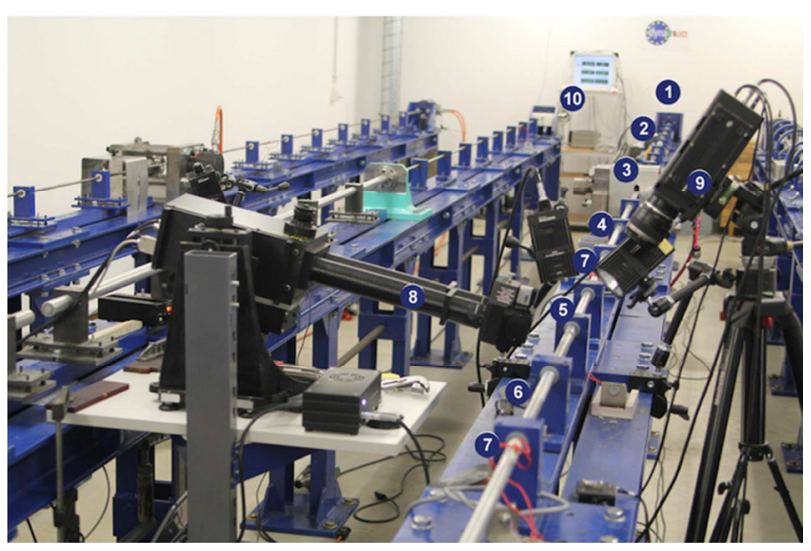

Fig. 2. Experimental set-up for specimens having $20 \mathrm{~mm}$ in diameter.

Fig. 2 and 3 show the photos of the two set-ups for specimens with $20 \mathrm{~mm}$ and $60 \mathrm{~mm}$, respectively. The numbers indicate: 1 . Hydraulic actuator; 2 . Pre-tensioned bar; 3. Blocking system; 4. Input bar; 5. UHPC Specimen; 6. Output bar; 7. Strain gauges station; 8. 
Electro-optic extensometer; 9. Fast-camera; 10. Fast transient recorders.

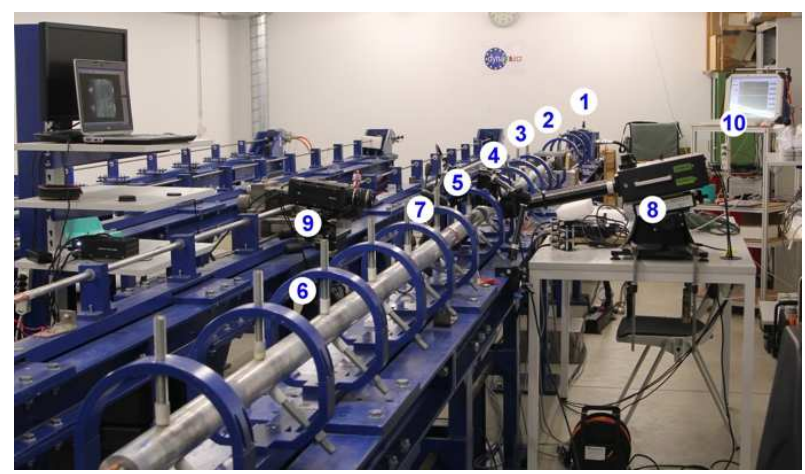

Fig. 3. Experimental set-up for specimens having $60 \mathrm{~mm}$ in diameter.

The UHPFRCs specimens have been tested by means of the modified Hopkinson bar device having input and output bars with a diameter of $60 \mathrm{~mm}$ (See Fig. 3).

Due to the length of the specimen $(60 \mathrm{~mm})$ the strain has not been obtained by the equation (2), but the specimen displacement is directly measured by means of an electro-optical Extensometer Rudolph GmbH (Model 200XR). which measure the movement of a black and white target placed between the two edges of the specimen-notch, as shown in Fig. 4. The stress has been obtained by equation (1).

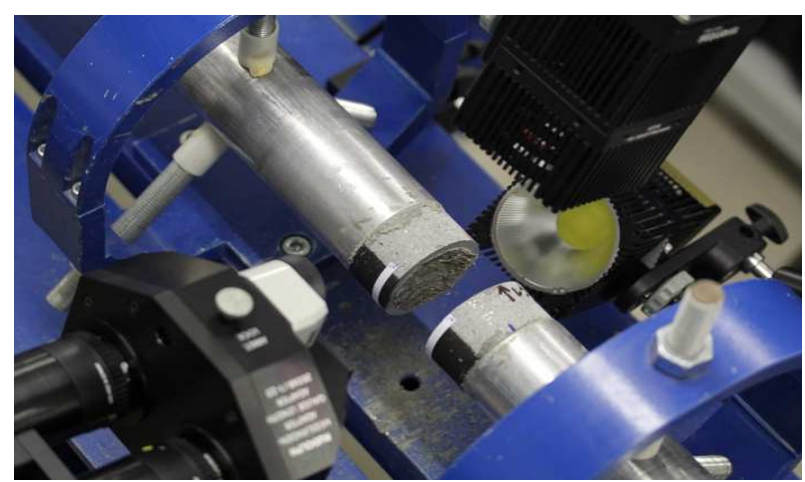

Fig. 4. Direct measurement of the displacements.

\section{Preliminary results}

\subsection{UHPC}

The first results have been obtained on the three matrixes tested at in a wide range of stress-rates. The medium and high stress rate tests have been performed in order to show the evolution of the strength with increasing the stress rate. The medium stress rate has been studied by means of a Hydro Pneumatic Machine [12-13].

Figs. 5, 6, and 7 depict the results of the three different matrixes in terms of dynamic tensile strength in function of the stress-rate. Considering as quasi-static tensile strength of the materials in Table 1 , it can be easily noted an important dynamic increase factor (DIF) for all three matrixes. At highest stress-rate the DIF is 2.37, 1.91, 2.28 for Matrix A, B, and C, respectively.

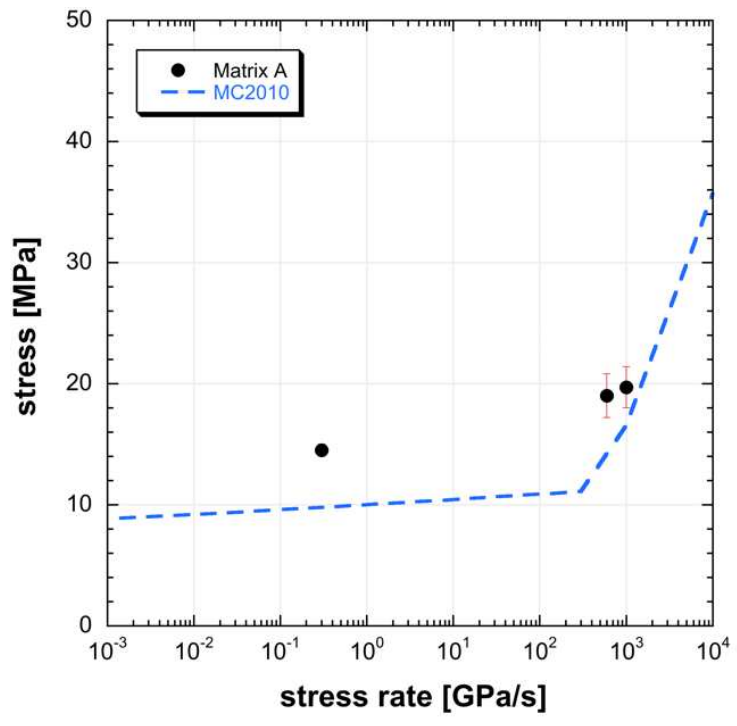

Fig. 5. Stress versus stress-rate for the Matrix A.

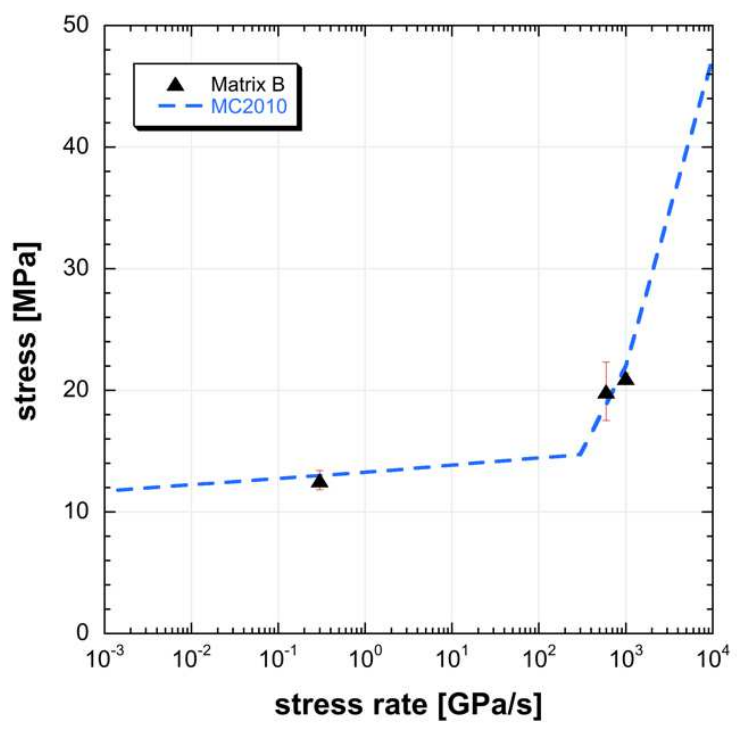

Fig. 6. Stress versus stress-rate for the Matrix B.

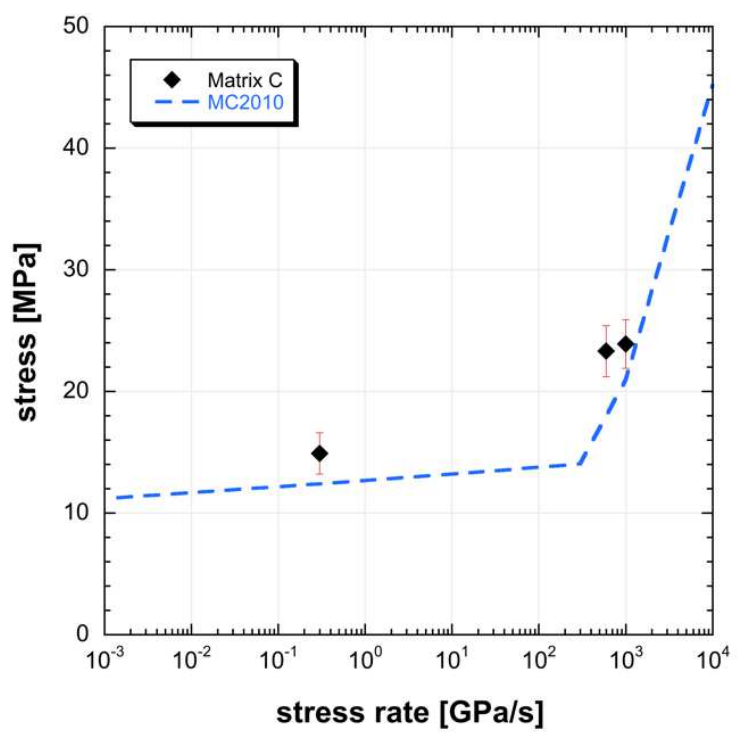

Fig. 7. Stress versus stress-rate for the Matrix C. 
As indicated in Model Code 2010 [26] the tensile strength under high rates of loading $f_{c t, i m p, k}$ can be estimated for a given stress rate as follows:

for $\dot{\sigma}_{t d} \leq 0.3 \cdot 10^{6} \mathrm{MPa} / \mathrm{s}$

$f_{c t, i m p, k}=f_{c t m}\left(\dot{\sigma}_{c t} / \dot{\sigma}_{c t 0}\right)^{0.018}$

for $\dot{\sigma}_{c t 0}>0.3 \cdot 10^{6} \mathrm{MPa} / \mathrm{s}$

$f_{c t, i m p, k}=f_{c t m} \cdot 0.0062\left(\dot{\sigma}_{c t} / \dot{\sigma}_{c t 0}\right)^{1 / 3}$

with $\dot{\sigma}_{c t 0}=0.03 \mathrm{MPa} / \mathrm{s}$.

For these matrixes the Model Code formulations provide quite good provision of the enhancement of matrix strength in function of the stress-rate. Further investigation will provide a more comprehensive understanding of the dynamic behaviour of such matrixes. In fact, that is of capital importance for the fibre reinforced materials (various Ductal ${ }^{\circledR}$ classes). Such data will provide designers better overview of relevant properties of these materials for design of protective structures.

\subsection{UHPFRC}

For a first evaluation of the UHPFRC material with two volumetric dosages $(2 \%$, and $3.25 \%)$ of steel micro fibres $(0.2 / 14 \mathrm{~mm}, 2500 \mathrm{MPa})$ the preliminary results are presented. In Figs. 8, 9, and 10 the stress versus time curves of the two volumetric dosages of fibres for the three matrixes are shown. The most relevant effects are in the increase both of the strength and post-peak stress.

In Fig. 11 the firsts stress versus crack opening displacement curves are depicted. The mean tensile postpeak resistance $\left(f_{c t f m}\right)$ measured at $0.3 \mathrm{~mm}$ crack opening has been confirmed in the direct tensile dynamic test for the Matrix B while for Matrix A an increase of $48 \%$ has been measured, finally for Matrix $\mathrm{C}$ has been observed a decrease of $30 \%$. The decrease of the mean tensile postpeak resistance for Matrix $\mathrm{C}$ was unexpected and can be possibly related to fibres orientation. Nevertheless, even the accidently lower behaviour would lead into deflection-hardening behaviour when used in structures [27]. Further tests should be performed to better understand impact of curing procedures.

The mechanical response of UHPFRC under high loading rate in tension can be considered linear-elastic up to matrix tensile strength localized in the notch is reached (see Fig. 12a). In these tests the damage is forced to stay in the notch area and after the first crack the loading transfer (bridging) is assured by fibres. Consequently, the stress decreases about linearly (the slope depends by the volumetric dosages of fibres) until the complete pull-out of fibres. Fig. 12 b) and c) show the images (recorded at $13,700 \mathrm{fps}$ ) of the notch in the post-peak region. Fig. 13 shows the photos of the specimen after the test.

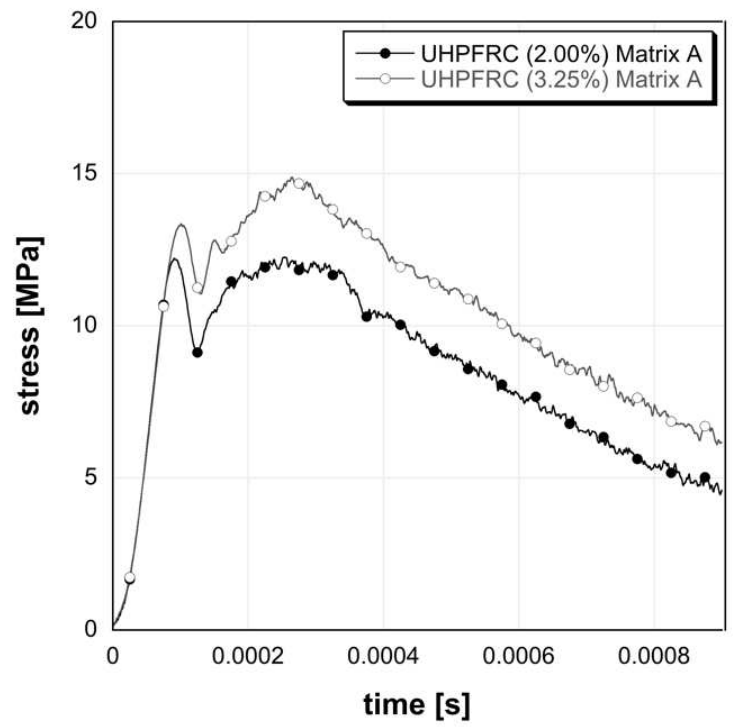

Fig. 8. Stress vs. time curves for Matrix A with $2.00 \%$ and $3.25 \%$ of fibre reinforcement.

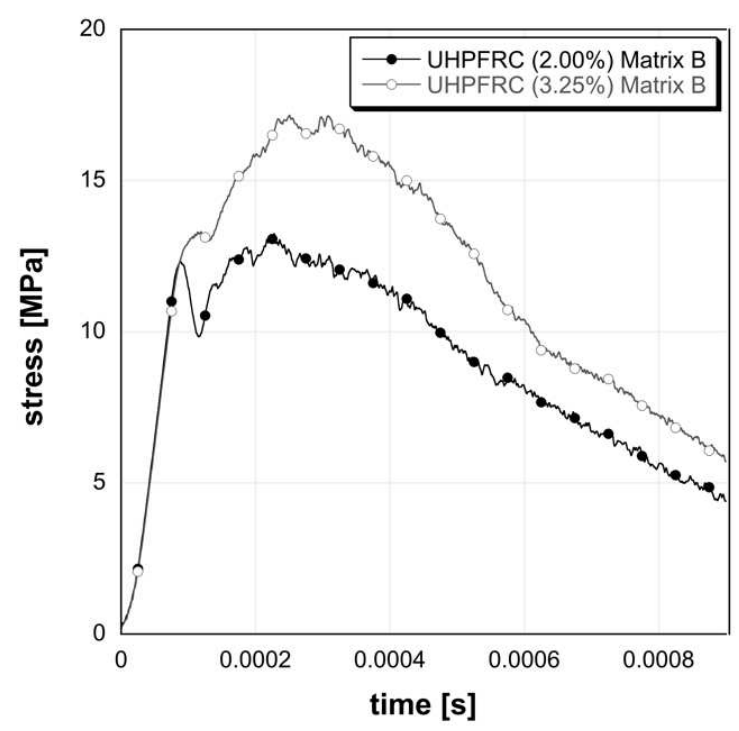

Fig. 9. Stress vs. time curves for Matrix B with $2.00 \%$ and $3.25 \%$ of fibre reinforcement.

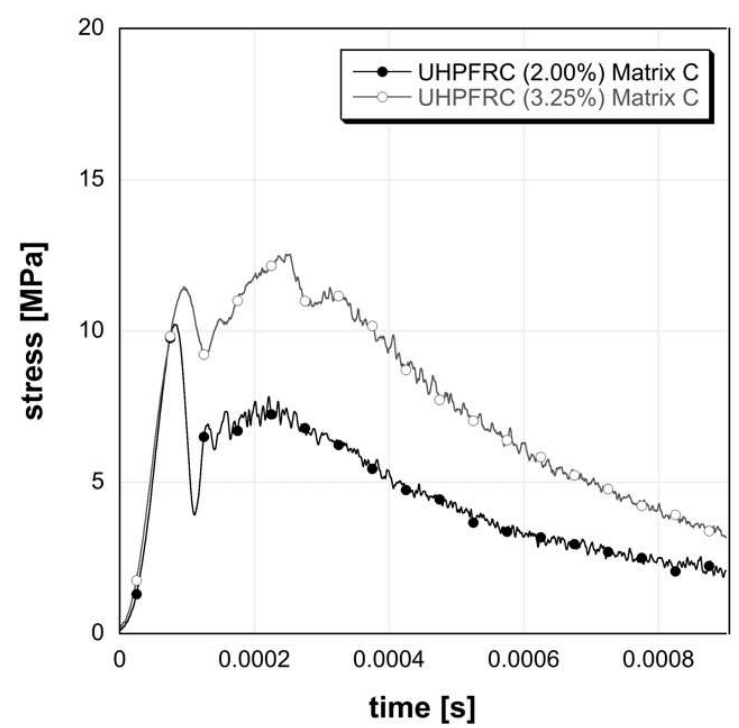

Fig. 10. Stress vs. time curves for Matrix $C$ with $2.00 \%$ and $3.25 \%$ of fibre reinforcement. 


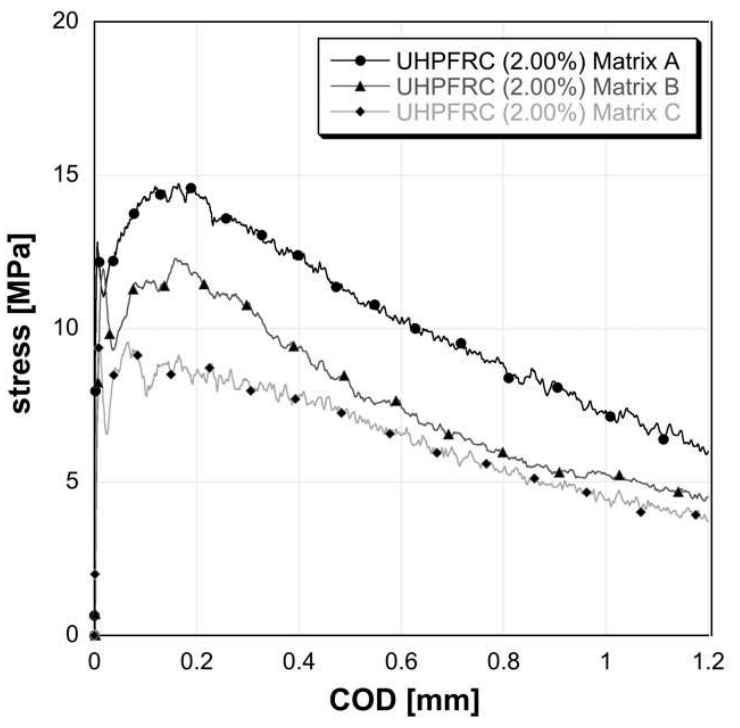

Fig. 11. Stress versus crack opening displacement curves for matrix $\mathrm{A}, \mathrm{B}$, and $\mathrm{C}$.

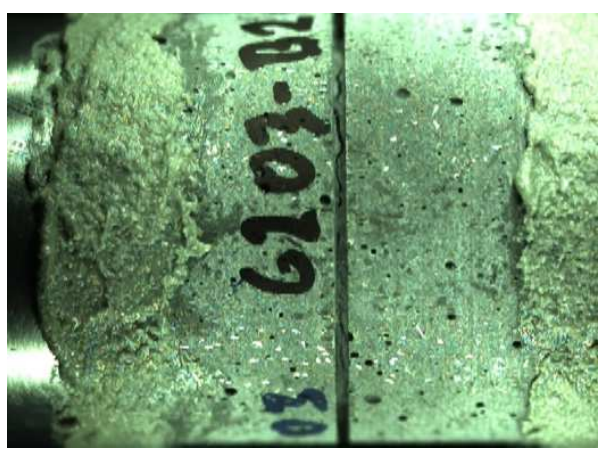

a)

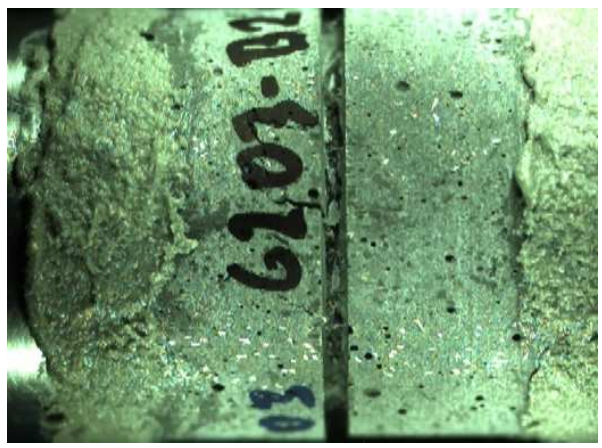

b)

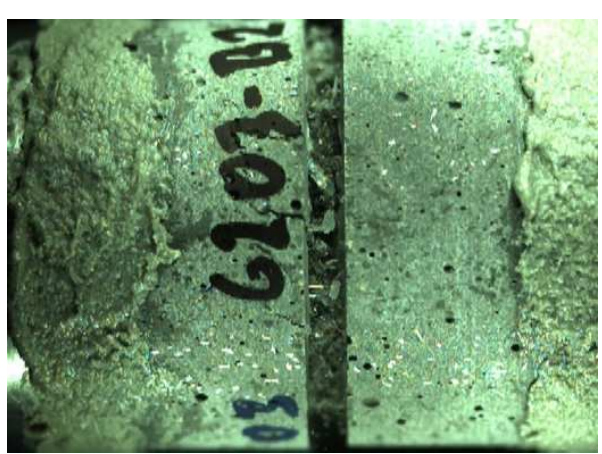

c)

Fig. 12. Photos of the failure process in the specimen notch.

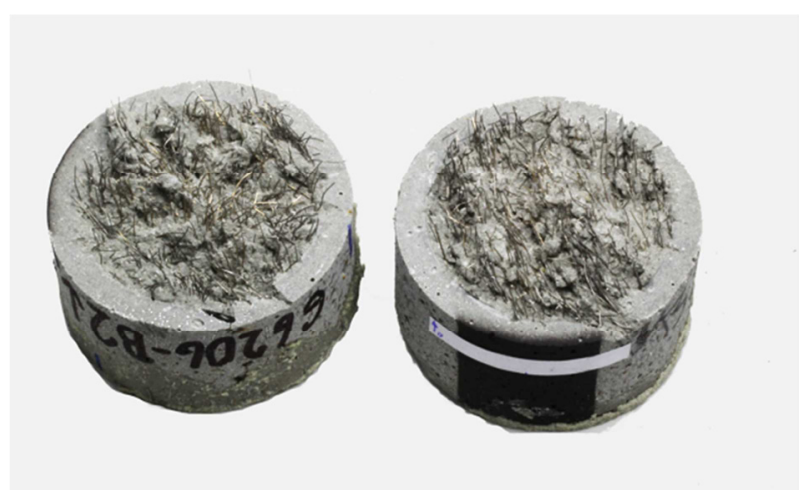

Fig. 13. Post-mortem photo of the specimen.

\section{Conclusions}

Three different types of matrix were investigated under intermediate and high stress rate loading regimes. The material characterization at different velocities was obtained by means of a Hydro-Pneumatic Machine and a Modified Hopkinson Bar device for the two abovementioned regimes. All the matrixes are influenced by the stress rate providing higher strength at higher stress rate.

The Matrix A highlights an increment of the tensile strength from the intermediate regime to the higher regime of $36 \%$, whilst Matrix B and Matrix $\mathrm{C}$ give an enhancement of $67 \%$ and $61 \%$, respectively.

The preliminary results of the fibers response at highstrain rates showed strain-hardening characteristics in the majority of cases. Even the unexpected/accidental result of the Matrix C with 2\% would show deflectionhardening when used in structures. The observed hardening behavior of Ductal ${ }^{\circledR}$ products is crucial for the outstanding energy dissipation. The strain-rate sensitivity of the post-peak responses is not yet defined. Nevertheless, the results indicated at least the same response as in the quasi-static conditions.

These data will be the basis for the analysis of the results of further testing campaign that will be carried out on several Ductal classes.

\section{References}

1. H.H. Bache, Densified Cement Ultra/Fine ParticleBased Materials.In:2 ${ }^{\text {nd }}$ Int. Conf. on Superplasticizers in Concrete, Ottawa, Canada (1981)

2. F. de Larrard, T. Sedran, Cem. Concr. Res. $24997-$ 1009 (1994)

3. P. Richard, M. Cheyrezy, ACI Sp. Pub. 144 507518 (1994)

4. P. Richard, M. Cheyrezy, Cem. Concr. Res. 25 (7) 1501-1511 (1995)

5. E. Cadoni, K. Labibes, M. Berra, M. Giangrasso, C. Albertini, ACI Mat. J 98, 220-223 (2001)

6. E. Cadoni, D. Forni, EPJ-ST, 225, 253-264 (2016) 
7. M. Foglar, R. Hajek, J. Fladr, J. Pachman, J. Stoller, Constr. Build. Mat., 145, 588-601 (2017)

8. R. Sovják, T. Vavřiník, P. Máca, J. Zatloukal, P. Konvalinka, Y. Song, Proc. Eng. 65, 120-125 (2013)

9. R.J. Thomas, A.D. Sorensen, Constr. Build. Mat. 153 846-856 (2017)

10. D.Y. Yoo, N. Banthia, Const.Build.Mat., 149, 416431 (2017)

11. NF $\mathrm{P}$ 18-470. Bétons - Bétons fibrés à Ultra Hautes Performances Spécification, performance, production et conformité, ISSN 0335-3931, AFNOR French Standards Institute (2016)

12. E. Cadoni, Rock Mech. Rock Engg, 43, 667-676 (2010)

13. S. Dobruský, D. Forni, E. Cadoni, Mechanical Characterization of UHPC at High Strain Rate, in Proc. of $6^{\text {th }}$ Int. Conf. on Design and Analysis of Protective Structures (DAPS 2017), Melbourne, pp. 107-112 (2017)

14. E. Cadoni, K. Labibes, C. Albertini, M. Berra, M. Giangrasso, Mat. Struct., 34, 21-26 (2001)

15. E. Cadoni, C. Albertini, G. Solomos, J. de Phys. IV 134, 647-652 (2006)

16. E. Cadoni, G. Solomos, C. Albertini, Mag. Concr. Res. 61(3), 221-230 (2009)
17. E. Cadoni, G. Solomos, C. Albertini, Mag. Conc. Res. 65(11), 660-672 (2013)

18. L. Coppola, E. Cadoni, D. Forni, A. Buoso, Appl. Mech. Mat. 82, 190-195 (2011)

19. L. Fenu, D. Forni, E. Cadoni, Comp. Part B: Engg 92(5) 142 - 150 (2016)

20. D. Asprone, E. Cadoni, F. Iucolano, A. Prota, Cem Concr Comp 53(10) 52-58 (2014)

21. E. Cadoni, 'Fracture behaviour of concrete at high strain rate', in proc. 'Fracture Mechanics of Concrete and Concrete Structures' (2013)

22. E. Cadoni, A. Meda, G. Plizzari, Mat Struct 42(9) 1283-1294 (2009)

23. A. Caverzan, E. Cadoni, M. di Prisco, Mech. Mat 59 $87-109$ (2013)

24. A. Caverzan, E. Cadoni, M. di Prisco, Int J Imp Engg 4528 - 38 (2012)

25. I. Curosu, V. Mechtcherine, D. Forni, E. Cadoni, Cem Concr Res 10216 - 28 (2017)

26. FIB, Model Code for Concrete Structures 2010, Ernst\&Sohn (2013)

27. G. Chanvillard, O. Roque, Behavior of fibre reinforced concrete cracked section under sustained load, PRO 6: 3rd Int. RILEM Workshop on High Performance Fiber Reinforced Cement Composites, Paris, 239 - 250 (1999) 